\title{
Effect of selenium on the development of selected indicators of fertility in dairy cows
}

\author{
A. Balicka-Ramisz ${ }^{1}$ and $G$. Jastrzębski²
}

1. Department of Biotechnology of Animal Reproduction and Environment Hygiene, West Pomerania University of Technology, Szczecin, Poland; 2. Municipal Office, Pyrzyce, Poland.

Corresponding author: A. Balicka-Ramisz, e-mail: abalicka52@gmail.com, GJ : anna.zakuro.vonramish93@gmail.com Received: 30-04-2014, Revised: 15-08-2014, Accepted: 17-09-2014, Published online: 26-10-2014

doi: 10.14202/vetworld.2014.863-867. How to cite this article: Balicka-Ramisz A, Jastrzębski G (2014) Effect of selenium on the development of selected indicators of fertility in dairy cows, Veterinary World 7(10): 863-867.

\begin{abstract}
Aim: The aim of this study was to determine selenium (Se) concentration in the blood serum of dairy cows and to establish its influence on the level of production and reproduction traits.

Materials and Methods: The study was performed on the farm located in Western Pomerania - Poland and involved 120 cows, which were selected using the analog method on the basis of their physiological state, lactation number, milk yield, age, and genotype. The following indices were analyzed in individual groups: Calving interval, gestation interval, insemination index, standstill of placenta. Se concentration in the blood serum was determined with the spectrofluorometric method.
\end{abstract}

Results: The mean serum Se concentration was in cows $0.038 \mu \mathrm{g} / \mathrm{ml}$. The use of Se preparations has raised fertility, which was documented statistically.

Conclusion: The study revealed that the problem of Se deficiency is still present in some dairy cattle herds in Western Pomerania - Poland.

Keywords: dairy cows, fertility rates, selenium, serum.

\section{Introduction}

One of the assumptions of welfare is to prevent diseases through the development and implementation to the practices of the culture of prevention programs that seek to ensure the profitability of livestock farming. Cattle is practically prone to deficiencies of minerals including selenium (Se), because it eats locally sourced feed. Proper levels of this biominerals affect the correct state of health as well as the proper functioning of the animals. Inadequate supplies of this element cause a reduction of its content in all the organs, which may lead directly to a decline in productivity and causes many enzootic diseases. In cattle, there are mainly two syndromes - Inflammation of the mammary gland and fertility disorders that affect the profitability of farms. One of the causes of these disorders is a low Se concentration in animals [1]. Se is now recognized as an essential trace element conditioning the proper growth and development of animals and humans. It is an essential component of animal organisms. Welfare disorders caused by a deficiency of Se can cause diseases such as oral muscular dystrophy (white muscle disease), mulberry heart disease, nutritional liver degeneration in pigs and wild boars (hepatosis diaetetica) [2], diarrhea in young ruminant, the increase in cases of metastatic liver necrosis in beef cattle, females may reach fetal death because of

Copyright: The authors. This article is an open access article licensed under the terms of the Creative Commons Attributin License (http:// creative commons.org/licenses/by/2.0) which permits unrestricted use, distribution and reproduction in any medium, provided the work is properly cited. their impaired development for retained placenta after birth and weakening the ability of breeding males.

The fertility disorders during the hiposplenozie include stopping bearings, which are subject to putrefaction, and at the hand peeling encountered considerable difficulties.

In bulls, Se affects mainly normal spermatozoids movement and makes them easier to penetrate the egg $[3,4]$. Se also plays an important role in the metabolism of the spermatozoids. In the examination of the frozen semen was found that this element contributes to the survival of spermatozoids in the temperature $38^{\circ} \mathrm{C}$ and the percentage of sperm with no defective after the acrosome after adding $1 \mu /$ Se to the extender [5].

To a large extent has been documented that Se significantly contributes to the development of animals and a number of metabolic processes as well as reproductive performance [6]. Especially, highmilk cows during the lactation are exposed to a deficiency of the trace element, which is excreted in breast milk [1,7]. There was also observed a significant correlation between serum levels of Se and the milk of cows [8]. Decreasing the level of biominerals in blood serum in lactating cows is a result of its secretion with milk $[9,10]$. It was also found that parenteral administration of Se significantly affects on its greater concentration in colostrum and milk [11]. There was demonstrated a close correlation between the occurrence of subclinical inflammation as lists and the level of Se in dairy herds [12]. There was demonstrated a close correlation between the occurrence of subclinical 
inflammation as lists and the level of Se in dairy herds. 24 dairy cows, with daily average milk production of $18.1 \mathrm{~kg}$, were fed diets containing different Se sources. The purpose of this paper was to evaluate the effects of such diets on milk production and quality on the occurrence of mastitis, and on physiological variables. However, both Se sources reduced the incidence of mastitis (subclinical positive mastitis and strongly positive mastitis) between the pre-experimental and experimental phases [13-15]. Administration of three subcutaneous injections of trace minerals had a positive impact on udder health, decreasing linear somatic cell count (SCC) scores, the incidence of subclinical mastitis, and (in multiparous cows) the incidence of clinical mastitis. In addition, trace mineral supplementation decreased the incidence of stillbirth parturition and endometritis. However, treatment did not have an effect on reproduction performance, milk production, and other health traits [16].

In nature, Se occurs unevenly, there are areas of soil rich in Se and low in this element. In Poland, there are vast areas low in Se. The content of Se in the soil was thoroughly Polish and the development as a map, wherein the content of the element ranged from 0.070 to $0.410 \mathrm{mg} / \mathrm{kg}$, depending on the type of. Western Pomerania is a region poor in this trace element where is found a low level of this element in the soil and plants [1]. The aim of the study was to determine the effect of administration of the preparations for the level of Se in serum and selected fertility of dairy cows in the area of Western Pomerania in Poland.

\section{Materials and Methods}

\section{Ethical approval}

All the procedures have been carried out in accordance with the guidelines laid down by theInstitutional Ethics Committee and in accordance with local laws and regulations

\section{Animal experimental procedures}

The study was conducted at the farm located in Western Pomerania in the north-western part of the Polish. In total, the research included 120 (3 groups with 40 animals in it) Holstein-Friesian cows that were selected by the analog method takes into account the physiological condition, the order of lactation, milk yield, age, and genotype. Nutrition cattle feed was based on the origin of farmyard. In the herd often observed the birth of weak calves and retained placenta.

There was adopted following experimental design:

1. The first group (I): Vitaminum E $(0.075 \mathrm{~g})$ and natrium selenosum (0.001095 g) was given to intramuscularly cows at a dose of $10 \mathrm{ml}$ per $1 \mathrm{cow}$

2. The second group (II): Sodium selenite was administered as a feed additive at a dose of $20 \mathrm{mg} / \mathrm{kg}$ feed for 14 days with an interval of 2 months

3. The third group (III) was a control group did not receive any Se supplements.
Blood was collected before the administration of Se, $48 \mathrm{~h}$ and 5 weeks after the application of formulations containing Se.

\section{Sampling and laboratory analyses}

All chemicals used were of analytical reagent grade. The concentration of Se was determined by spectrofluorimetric method using 2,3-diaminonaphthalene, following wet mineralization in a mixture of concentrated HNO3 and HClO4 acids. Se was determined in accordance with the method described by Pilarczyk et al. Fluorescence was measured in the organic (cyclohexane) layer using an emission wavelength of $518 \mathrm{~nm}$ and an excitation wavelength of $378 \mathrm{~nm}$ [17].

\section{Statistical analyses}

For the verification of statistical data were used computer program STATISTICA 7.1.PL. There were calculated the mean (), standard deviation (S), and coefficient of variation (V). Univariate and two-way analysis of variance, and the significance of differences between the means of the groups were calculated using Duncan's test.

\section{Results}

Results of studies of the level of Se in serum of dairy cows kept on a farm in Western Pomerania are summarized in Table- 1 . The average concentration of Se in the tested cows feeding with the farm fodder without the addition of Se was $0.038 \mathrm{mg} / \mathrm{ml}$.

The lowest Se levels in serum were found in cows in the control group $(0.04 \mathrm{mg} / \mathrm{ml})$, and the highest in Group I, where the cows are given preparation sodium selenite and vitamin E (0.08 ug/m). Statistically significant differences $(\mathrm{p} \leq 0.01)$ between the average content of Se in serum of cows from the control group and the average contents of Se group, experimental Se dosed preparations.

In our study, the shortest average calving interval and gestation interval characterized by experimental cows treated with the preparation, and they were at 379.5 and 103 days. A cow in the control group was the longest periods and was 429.8 and 151.1 days. The average length of the analyzed periods was statistically significant $(\mathrm{p} \leq 0.05)$ in both treatment groups compared to the control group (Table-2). Insemination index was lower in cows that are used Se preparations, however, was not confirmed statistically. A high index of insemination involves additional financial expenditures and may adversely affect the profitability of production [18]. The lowest percentage of retained

Table-1: The Se level in blood serum of cows.

\begin{tabular}{lcccc}
\hline Group & $\mathbf{N}$ & $\bar{\chi}$ & $\mathbf{S}$ & $\mathbf{V}(\%)$ \\
\hline I & 40 & $0.08^{\mathrm{A}, \mathrm{C}}$ & 0.006 & 7 \\
II & 40 & $0.06^{\mathrm{B}, \mathrm{C}}$ & 0.007 & 11 \\
$\mathrm{III}$ & 40 & $0.04^{\mathrm{A}, \mathrm{B}}$ & 0.004 & 11 \\
\hline
\end{tabular}

$\mathrm{A}, \mathrm{B}, \mathrm{C}$ Statistical significant differences by $\mathrm{p} \leq 0.01$, $\mathrm{N}=$ Number of cows, $\mathrm{Se}=$ Selenium 
Table-2: The select fertility rates in examined cows.

\begin{tabular}{|c|c|c|c|c|c|c|c|c|c|}
\hline \multirow[t]{2}{*}{ Specification } & \multicolumn{3}{|c|}{ Group I } & \multicolumn{3}{|c|}{ Group II } & \multicolumn{3}{|c|}{ Group III } \\
\hline & $\bar{\chi}$ & $\mathbf{S}$ & V (\%) & $\bar{\chi}$ & $\mathbf{s}$ & V (\%) & $\bar{\chi}$ & $\mathbf{S}$ & $\mathbf{v}(\%)$ \\
\hline Calving interval (days) & $379.5^{a}$ & 46.47 & 12 & $381.4^{\mathrm{b}}$ & 36.52 & 10 & $429.8^{a b}$ & 70.63 & 16 \\
\hline Gestation interval (days) & $103.3^{a}$ & 37.67 & 36 & $107.0^{\mathrm{b}}$ & 36.63 & 34 & $151.1^{\mathrm{ab}}$ & 65.59 & 43 \\
\hline Insemination index & 2 & 1.35 & & 2.3 & & 46 & 2.4 & 1.6 & 67 \\
\hline
\end{tabular}

abStatistical significant differences by $\mathrm{P} \leq 0.05$

placenta after birth was found in Group I - 8.49\% for the control Group - 12.12\% (Table-3).

\section{Discussion}

Studies on the enrichment of various forms of Se diets were carried out in a number of research centers around the world. Ruminants Se is well-absorbed both from organic and inorganic. However, the ability to absorb inorganic Se is low due to the specific environment in the rumen. Microorganisms which are rumen microflora reduce inorganic Se into a form in which the element is absorbed tren [19]. In studies using Se yeast as a feed additive in doses of 2 and $6 \mathrm{mg}$ Se/day found no apparent effect of this element to increase the milk yield. However, the incidence was observed in dairy cows udder infections and mastitis [14]. There was also assessed the effect of Se supplementation on the development of somatic cells in milk (SCC) in dairy cows. In cows that were fed a diet containing suboptimal concentrations of Se $(<0.05 \mathrm{ppm}$ in the dry matter), showed an increase in blood glutathione peroxidase- 1 activity, which contributed to the decline in the number of somatic cells in milk [12]. The results indicate that lipid microencapsulation has the potential to protect nutrients from complete rumen reduction and that Se from microencapsulated selenite is incorporated in milk more efficiently than the free form. Microencapsulated sodium selenite was shown to be comparable to Se-yeast in terms of availability and incorporation in milk when fed at $0.3 \mathrm{mg} / \mathrm{kg}$ diabetes mellitus (DM), whereas the inclusion in the diet at $0.5 \mathrm{mg} / \mathrm{kg}$ DM resulted in higher plasma and milk concentrations than selenized yeast [20]. It was described the linear dependencies between the content of Se in feed and the serum and breast milk in cattle. Se supplementation to dairy cattle diets increased the Se content of milk. Organic Se compounds are more effective and showed a higher total carry over rate into the milk than inorganic Se sources. Due to considerable variation of Se in food of animal origin, European Food Safety Authority recommended that the Se-supplementation from organo-Se-compounds should not exceed a maximum of $0.2 \mathrm{mg} / \mathrm{kg}$ complete feed [21]. The concentration of Se in whole blood was more variable than that in milk, and took much longer to respond to change in Se status, but it was not affected by diet at any time either. For the on-farm production of Se-enriched milk, it is important to be able to predict milk Se concentration from Se input. In our study, type of diet did not affect
Table-3: Time of placenta isolation (in hours) after birth in cows in examined herds.

\begin{tabular}{lccc}
\hline Specification & \multicolumn{3}{c}{ N (\%) } \\
\cline { 2 - 4 } & Group I & Group I I & Group I I I \\
\hline Until 6 h & $17(68.41)$ & $16(65.62)$ & $18(54.55)$ \\
From 6 to 12 h & $5(20.41)$ & $6(21.31)$ & $8(24.24)$ \\
Above 12 h & $1(4.0)$ & $2(4.21)$ & $3(9.09)$ \\
Standstill of placenta & $2(8.49)$ & $3(9.10)$ & $4(12.12)$ \\
Generally & $25(100)$ & $24(100)$ & $33(100)$ \\
\hline
\end{tabular}

this relationship [22]. Use as a feed additive preparations containing with Saccharomyces cerevisiae Se resulted in higher $(\mathrm{p}<0.05)$, the milk yield, the content of energy, protein, and dry weight of non-fat compared to the control group [23]. In Poland, in recent years has conducted research on the content of tailored minerals including Se in milk and the hair of cows from organic farms. In examining the correlation between microelements found them. High and positive correlation between the content of major elements $(\mathrm{K}, \mathrm{Mg})$ and Se. Obtained results were better, but they were not statistically significant [10]. The bioavailability of Se was investigated using various forms of administration of the preparations. Found to increase the level of Se in the blood and milk of cows that received formulations Se. Se molar level ranged from $0.09 \mathrm{mg} / \mathrm{L}$ to $0.52 \mathrm{mg} / \mathrm{L}$ depending on the form of administration, the dose and the time of year. This discrepancy the authors explain the lack of significant correlation between Se in milk and blood [24]. The use of seleno-yeast as a Se supplement in free-choice minerals compared to sodium selenite increased the whole blood Se concentration of both cows and their nursing calves [25]. Research on the use of bio-preparations containing Se, which was administered to dairy cows showed higher concentration of macronutrients, vitamins, and higher levels of biochemical markers (glucose, protein) in their serum [24]. Similar indicators (increased mineral content in milk and blood serum) in cattle were obtained after administration of preparations containing yeast [26]. Searched the relationship between the concentration of Se in serum of dairy cows and its effect on the development and reproductive traits of these animals. It was found that the average content of fat and protein in the milk of cows was the greatest in animals limit concentration (the content of 0.041-0.079 ppm) Se and significantly different $(\mathrm{p} \leq 0.01)$ compared to a group of deficiency and physiological concentrations of Se [27]. As one 
of the causes of fertility disorders and mastitis is considered low concentration of this element in the body. The consequence of stopping the bearings is acute or chronic inflammation of the lining of the uterus and ovaries cyst [28]. It has been calculated that the losses in the European Union caused by the retention of fetal membranes per cow amount to 295 euros [29]. Several studies have shown that supplementation of inorganic and organic forms of Se improved rates of reproduction problems including the retention of the bearings. The positive use of Se preparations, which caused a decrease in bearing announces arrest of many authors. This problem is particularly concerned higher producing herds of cows by dietary supplementation with Se-enriched preparations were reductions in retained placenta: Multiparous $15 \%$ and $7 \%$ of the root [30]. It was also observed a decrease of the bearing retention 51.2-8.8\% in flocks where chronically observed phenomena and 3 times the reduction in the number of retained [31].

\section{Conclusion}

Own research, as well as other authors, have reported a positive effect Se supplements to improve fertility of cows selected. Before using dietary, supplementation is needed earlier accurate diagnosis of the level of Se in cattle.

\section{Authors' Contributions}

ABR and JG made the laboratory part of the research in the Department of Biotechnology of Animal Reproduction and Environment Hygiene, West Pomerania University of Technology. Both authors contributed equally in the research. Both authors read and approved the final manuscript

\section{Acknowledgments}

The financial support and facilities provided by Department of Biotechnology of Animal Reproduction and Environment Hygiene, West Pomerania University of Technology; Szczecin Poland.

\section{Competing I nterests} interests.

The authors declare that they have no competing

\section{References}

1. Dębski, B. (2007) Evaluation of selenium level in animals in Poland. In: Selenium - An Element that Matters to Health and Fascinates Researchers. Malamut, Warszawa. p103-126.

2. Bostedt, H. and Schramel, P. (1990) The importance of selenium in the prenatal and postnatal development of calves and lambs. Biol. Trace Elem. Res., 24: 163-171.

3. Pavlata, L., Prášek, J., Podhorský, A., Pechová, A. and Haloun, T. (2003) Selenium metabolism in cattle: Maternal transfer of selenium to newborn calves at different selenium concentrations in dams. Acta. Vet. Brno., 72: 639-646.

4. Sengupta, D. and Nandi, PR. (2013) Effect of estradiol, vitamin $\mathrm{A}, \mathrm{E}$ and selenium treatment with varying sexual rest period on recovery rate in cross-bred cows with chronic endometritis. Vet. World, 6(2): 106-108.
5. Udała, J., Błaszczyk, B. and Zdanowicz, A. (2001) Effect of selenium on biological value of bull semen. Folia Agric. Stein. Zootec., 42: 163-168.

6. Hartley, W.J. and Grant, A.B. (1961) A review of selenium responsive diseases of New Zealand. Livestock, 20: 679-688.

7. Horton, S.A. and Mccarthy, F.D. (1986) Use of injectable vitamin $\mathrm{E}$ and selenium-vitamin $\mathrm{E}$ emulsion in ewes and suckling lambs to prevent nutritional muscular dystrophy. J. Anim. Sci., 62: 497-508.

8. Pilarczyk, B., Balicka-Ramisz, A., Ramisz, A., Pilarczyk, R., Sablik, P. and Wójcik, J. (2008) Selengehalte im blutserum von aus Deutschland, Tschechien, Frankreich und Holland nach Polen importierten Rindern. Tierärztl. Umschau., 63: 243-246.

9. Dębsk,i B. (1992) Indicatory role of milk in hyposelenosis evaluation in cattle. Dissertation. SGGW, Warszawa.

10. Bombik, T., Bombik, E., Górski, K., Rymsza, K. and Saba, L. (2010) Selenium content in feed and cows' blood serum in the central-eastern Poland. Bull. Vet. Inst. Puławy, 54: 273-276.

11. Gabryszuk, M., Słoniewski, K., Metera, E. and Sakowski, T. (2010) Content of mineral elements in milk and hair of cows from organic farms. J. Elementol., 5(2): 259-226.

12. Cuesta P.A., McDowell, L.R., Kunkle, W.E., Wilkinson, N.S. and Martin, F.G. (1995) Effects of high-dose preparatum injections of Se and vitamin E on milk and serum concentrations in ewes. Small Ruminant Res., 18: 99-103.

13. Koller, L.D., Whitbeck, G.A. and South, P.J. (1984) Transplacental transfer and colostrums concentrations of selenium in beef cattle. Am. J. Vet. Res., 45: 2507-2510.

14. Oltramari, C.E., Pinheiro, M., Miranda, M. S., Arcaro, J.R.P., Toledo, M., Ambrósio, L.A., Leme, P.R., Manella, M.Q. and Júnior, I.A. (2014) Selenium sources in the diet of dairy cows and their effects on milk production and quality, on udder health and on physiological indicators of heat stress. Ital. J. Anim. Sci., 13: 48-52.

15. Davidov, I., Erdeljan, M., Radinović, M., Stančić, I. and Kovačević, Z. (2013) Blood selenium concentration affect mastitis and milk quality in dairy cows. J. Microbiol. Biotechnol. Food Sci., 2: 1147-1154.

16. Machado, V.S, Bicalho, M.L.S., Pereira, R.V., Caixeta, L.S., Knauer, W.A., Oikonomou, V., Gilbert, R.O. and Bicalho, R.C. (2013) Effect of an injectable trace mineral supplement containing selenium,copper, zinc, and manganese on the health and production of lactating Holstein cows. Vet. J., 197: 451-456.

17. Pilarczyk, B., Tomza-Marciniak, A., MituniewiczMałek, A., Wieczorek, M., Pilarczyk, R., Wójcik, J., Balicka-Ramisz, A., Bąkowska, M. and Dmytrów, I. (2010) Selenium content in selected products of animal origin and estimation of the degree of cover daily Se requirement in Poland. Int. J. Food Sci. Technol., 45: 186-191.

18. Ramisz, A., Balicka-Ramisz, A. and Jastrzębski, G. (2012) Selenium concentration in dairy cows and its influence on production traits. Acta Sci. Pol., Zoot., 11(1): 49-58.

19. McIntosh, G. and Royle, P. (2002) Supplementation of cows with organic selenium and the identification of selenium-rich protein fractions in milk. In: Lyons, T. and Jacques, K. editors. Nutritional Biotechnology in the Feed and Food Industries: Proceedings of Alltech's $18^{\text {th }}$ Annual Symposium. Nottingham University Press, Nottingham, UK. p233-238.

20. Grilli, E., Gallo, A., Fustini, M., Fantinati, P. and Piva, A. (2013) Microencapsulated sodium selenite supplementation in dairy cows: Effects on selenium status. Animal, 7: 1944-1949.

21. Meyer, U., Heerdegen, K., Schenkel, H., Dänicke, S and Flachowsky, G. (2014) Influence of various selenium sources on selenium concentration in the milk of dairy cows. J. Verbraucherschutz und Lebensmittelsicherheit, 9: 1-9. 
22. Stockdale, C.R., Shields, P.M., McKenna, A., Walker, G.P., Dunshea, F.R. and Doyle, P.T. (2011) Selenium levels in cows fed pasture and concentrates or a total mixed ration and supplemented with selenized yeast to produce milk with supra-nutritional selenium concentrations J. Dairy Sci., 94: 262-272.

23. Abd El-Ghani, A.A. (2004) Influence of diet supplementation with yeast culture (Saccharomyces cerevisiae) on performance of Zaraibi goats. Small Rumin. Res., 52: 223-229.

24. Dobrzański, Z., Górecka, H., Opaliński, S., Chojnacka, K. and Kołacz, R. (2005) Trace and ultra-trace elements in cow's milk and blood. Med. Wet., 61(3): 301-304. (in Polish).

25. Gunter, S.A., Beck, P.A. and Hallford, D.M. (2013) Effects of supplementary selenium source on the blood parameters in beef cows and their nursing calves. Biol. Trace Elem. Res., 152: 204-211.

26. Dobrzański, Z., Dolińska, B., Chojnacka, K., Opaliński, S. and Ryszka, F. (2006) The use of yeasts in livestock feeding.
Acta Sci. Pol. Med. Vet., 5(2): 49-66. (in Polish).

27. Korniewicz, A., Kinal, S., Korniewicz, D. and Białoń, K. (2005) Effect of diamond V XP yeas culture feed supplement on production and composition of cow milk. Acta. Sci. Pol. Zoot., 4(1): 81-94.

28. Adamski, M. and Świerkowski, K. (2004) Analysis of the correlation between body condition of dairy cows and chosen parameters of reproduction. Sci. J. Wrocław. Zoot., 505: 27-33

29. Gnemmi, G. (2002) Therapeutic protocol of reproductive pathologies of the postpartum cow. Press Conference PTNW, Wenecja k/Żnina, Poland, 19.10-20.10, p. 25-31.

30. Eger, S., Drori, D., Kadoori, I., Miller, N. and Schindler, H. (1985) Effects of selenium and vitamin $\mathrm{E}$ on incidence retained placenta. J. Dairy Sci., 68(8): 2119-2122.

31. Muller, F.J., Miller, J.K., Ramsey, N., DeLost, R.C. and Madsen, F.C. (1989) Effect of vitamin E and excess iron on placental retention and subsequent milk yield in dairy cows. J. Dairy Sci., 72: 564. 